\title{
Recent increase in detection of alprazolam in Victorian heroin-related deaths
}

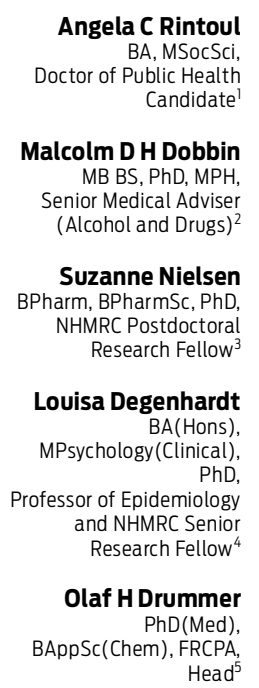

1 Department of Epidemiology and

Preventive Medicine,

Monash University,

Melbourne, VIC.

2 Mental Health, Drugs and

Regions Division,

Department of

Health, Victoria,

Melbourne, VIC.

3 Discipline of Addiction

University of Sydney,

Sydney, NSW.

4 National Drug and

Alcohol Research Centre University of

New South Wales,

Sydney, NSW.

5 Department of

Forensic Medicine

Monash University,

Melbourne, VIC

angela.rintoul@ monash.edu

MJA 2013; 198: 206-209 doi: 10.5694/mjal2.10986

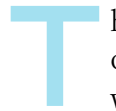

he use of benzodiazepines by opioid-dependent people is widespread. ${ }^{1-4}$ The 2011 Victorian Illicit Drug Reporting System (IDRS), a sentinel survey of people who inject drugs (PWID), reported $92 \%$ lifetime and $71 \%$ recent (in the past 6 months) use among PWID. ${ }^{5}$ PWID use benzodiazepines for a number of reasons: to enhance the intoxicating effects of heroin or other opioids, manage anxiety, or manage withdrawal symptoms. ${ }^{3}$

The contribution of benzodiazepines to heroin overdose is well established. ${ }^{6,7}$ Alprazolam is a benzodiazepine registered in Australia for short-term treatment of anxiety and panic disorder. It is not recommended as first-line treatment because of concerns about risks of dependence and its potential for misuse. ${ }^{4,8}$

Alprazolam, like other commonly misused drugs, has a rapid onset and offset of action and high potency. ${ }^{8}$ Alprazolam may also be more toxic in overdose than other benzodiazepines. ${ }^{9}$ Laboratory-based studies have found that in combination with methadone, alprazolam has significant effects on respiration. ${ }^{10} \mathrm{~A}$ review of the interaction concluded that most evidence suggests the interaction is pharmacodynamic in nature. ${ }^{11}$

Victorian IDRS reports showed recent alprazolam use increased from $8 \%$ in $2005^{12}$ to $69 \%$ in $2011 .^{5}$ Alprazolam is now the most commonly injected benzodiazepine, ${ }^{5}$ with a reported street price of three tablets for $\$ 10 .{ }^{13}$ Alprazolam use is associated with disproportionate levels of harm, including amnesia, violent outbursts of rage in otherwise non-violent individuals, and theft. ${ }^{1,13-15}$ In Victoria, most alprazolam (81\%) used by PWID in 2011 was obtained from illicit sources. $^{5}$

Given the increased number of episodes of serious harm associated with alprazolam use, we aimed to examine its public health impact, to inform prescribing and to guide appropriate policy responses. We investigated trends in alprazolam prescribing and

\section{Abstract. \\ Objectives: To examine the rate of detection of alprazolam among cases of heroin-related death (HRD) in Victoria, including the relationship between} alprazolam supply and HRDs.

Design and setting: Population-based study of community alprazolam supply in Victoria and HRDs reported to the Victorian coroner from January 1990 to December 2010.

Main outcome measures: Number of prescriptions for alprazolam supplied; defined daily dose (DDD) per 1000 population per day of alprazolam; number of cases of HRD in which alprazolam was detected through postmortem toxicological testing.

Results: Alprazolam supply increased by $1426 \%$, from 0.42 DDD/1000/day in 1990, to 6.41 in 2010. For every 1 unit increase in DDD/1000/day, the proportion of cases of HRD in which alprazolam was detected increased at an incidence rate ratio of $2.4(95 \% \mathrm{Cl}, 2.1-2.8 ; P<0.001)$. Alprazolam was detected among increasing proportions of HRDs, from 5.3\% in 2005 to a peak of $35.3 \%$ in 2009.

Conclusion: The increase in detection of alprazolam among cases of HRD, particularly since 2005, and the disproportionate increase in prescribing of the high-dose $2 \mathrm{mg}$ formulation compared with other formulations suggest a need to examine alprazolam prescribing and to identify inappropriate prescribing and the circumstances of diversion from licit to illicit use.

its detection in heroin-related deaths (HRDs) in Victoria. Our hypothesis was that increased mean consumption of alprazolam is likely to have significant effects on heroin users, ${ }^{16}$ a population already vulnerable to drug toxicity.

\section{Methods}

\section{Victorian prescription estimates}

Estimates of prescription numbers for all dose formulations of alprazolam dispensed in Victoria for each calendar year, 1990-2010, were calculated from national supply data, Australian Statistics on Medicines (ASM), published by the Pharmaceutical Benefits Advisory Committee Drug Utilisation Sub-Committee. We determined the annual proportion of Pharmaceutical Benefits Scheme (PBS) supply to Victoria using data from Medicare Australia and applied this proportion to the annual ASM data. The ASM data provide a more complete estimate of alprazolam supply, as they include both private non-PBS prescriptions (those that do not attract a PBS subsidy) and PBS prescription numbers.

A defined daily dose per 1000 population per day (DDD/1000/day) for Victoria was calculated for each year using the same Victorian proportions derived from the PBS figures, the DDD for alprazolam $(1 \mathrm{mg}){ }^{17}$ the base number of estimated alprazolam prescriptions in Victoria, the usual pack size (50 tablets) for each dose formulation and Victorian population data.

\section{Alprazolam detection in heroin-related deaths}

Annual aggregate numbers of HRDs and annual numbers of cases of HRD in which alprazolam was detected were extracted from the Victorian Institute of Forensic Medicine toxicology database. Cases reported to the Victorian coroner in the 21-year period 1990-2010 that were classified as drug-related deaths, involved heroin and had been subjected to toxicology testing were included. All cases had results for a full range of toxicology tests, including for ethanol and common drugs of misuse. All presumptive detections had been confirmed by appropriate analytical techniques. Alprazolam had been tested for, using both immunoassay class tests on urine or blood (depending on availability of specimens) and gas chromatographymass spectrometry on blood. All detections had been confirmed and quantified in blood using validated methods. 
1 Heroin-related deaths (HRDs) and detection of alprazolam, Victoria, 1996-2010*

\begin{tabular}{|c|c|c|c|c|c|c|c|c|c|c|c|c|c|c|c|}
\hline Parameter & 1996 & 1997 & 1998 & 1999 & 2000 & 2001 & 2002 & 2003 & 2004 & 2005 & 2006 & 2007 & 2008 & 2009 & 2010 \\
\hline Total number of HRDs & 147 & 157 & 265 & 362 & 331 & 47 & 51 & 90 & 84 & 57 & 26 & 36 & 76 & 51 & 96 \\
\hline $\begin{array}{l}\text { Alprazolam detected, } \\
\text { no. (\%) }\end{array}$ & $\begin{array}{c}2 \\
(1.4 \%)\end{array}$ & $\left(\begin{array}{c}1 \\
(0.6 \%)\end{array}\right.$ & $\begin{array}{c}3 \\
(1.1 \%)\end{array}$ & $\begin{array}{c}7 \\
(1.9 \%)\end{array}$ & $\begin{array}{c}4 \\
(1.2 \%)\end{array}$ & $\begin{array}{c}0 \\
(0.0)\end{array}$ & $\begin{array}{c}2 \\
(3.9 \%)\end{array}$ & $\begin{array}{c}4 \\
(4.4 \%)\end{array}$ & $\begin{array}{c}2 \\
(2.4 \%)\end{array}$ & $\begin{array}{c}3 \\
(5.3 \%)\end{array}$ & $\begin{array}{c}3 \\
(11.5 \%)\end{array}$ & $\begin{array}{c}6 \\
(16.7 \%)\end{array}$ & $\begin{array}{c}13 \\
(17.1 \%)\end{array}$ & $\begin{array}{c}18 \\
(35.3 \%)\end{array}$ & $\begin{array}{c}27 \\
(28.1 \%)\end{array}$ \\
\hline $\begin{array}{l}\text { No. of alprazolam } \\
\text { prescriptions ('OOOs) }\end{array}$ & 95 & 100 & 119 & 119 & 134 & 145 & 150 & 161 & 174 & 179 & 188 & 217 & 236 & 246 & 240 \\
\hline $\begin{array}{l}\text { Alprazolam prescriptions } \\
\text { per } 100000 \text { population }^{\dagger}\end{array}$ & 2087 & 2170 & 2559 & 2533 & 2828 & $\begin{array}{r}301 \\
2\end{array}$ & 3074 & 3257 & 3488 & 3526 & 3653 & 4146 & 4431 & 4528 & 4327 \\
\hline $\begin{array}{l}\text { Defined daily dose/1000 } \\
\text { population/day }\end{array}$ & 2.06 & 2.22 & 2.68 & 2.86 & 3.25 & 3.52 & 3.70 & 4.00 & 4.36 & 4.54 & 4.77 & 5.48 & 6.06 & 6.58 & 6.41 \\
\hline
\end{tabular}

*1990-1995 not shown (there were no HRDs involving alprazolam during this period). $†$ The proportion dispensed in Victoria was estimated using national Medicare data on Pharmaceutical Benefits Scheme supply of all formulations and this was applied to Australian Statistics on Medicines supply data (see Methods).

Ethics approval was granted by the Victorian Institute of Forensic Medicine Research Advisory Committee.

\section{Statistical analysis}

We used a Poisson regression model to assess the relationship between estimated trends in alprazolam supply and HRDs involving alprazolam. All statistical tests adjusted for annual fluctuations in HRDs. Data were analysed using Stata, version 11 (StataCorp).

\section{Results}

\section{Alprazolam prescribing}

Alprazolam supply increased by $1426 \%$ from $0.42 \mathrm{DDD} / 1000 /$ day in 1990 to 6.41 DDD/1000/day in 2010 (Box 1). The estimated number of Victorian prescriptions for alprazolam increased by $611 \%$, from $609 / 100000$ population in 1990 to $4327 / 100000$ population in 2010 (Box 1). The most remarkable change was in prescriptions for the $2 \mathrm{mg}$ formulation, which increased from $4.1 \%$ to $27.9 \%$ of the populationadjusted rate for alprazolam prescriptions between 1998 and 2010. Box 2 shows trends in total DDD/1000/day for the four alprazolam dose formulations. A large proportion of alprazolam prescriptions were private; in 2009, private prescriptions accounted for $37.2 \%$ of all prescriptions.

\section{Heroin-related deaths}

There were 2392 HRDs in Victoria from 1990 to 2010. The annual number varied considerably over this time, with a large increase in HRDs per year from 1993, peaking at 362 deaths in 1999 (Box 1). A large decrease in HRDs reflected a reduction in heroin supply in 2001, and numbers subsequently fluctuated between 26 and 76 HRDs per year from 2001 to 2009, increasing to 96 in 2010 (Box 1, Box 3).

The number of alprazolam detections increased steadily from 2004 , reaching a peak in 2010. Detection fluctuated between 0 and $4.4 \%$ of HRDs from 1990 to 2004, with a large increase from $5.2 \%$ in 2005 to $35.3 \%$ in 2009 , decreasing to $28.1 \%$ in 2010 (Box 1, Box 3).

The Poisson regression model showed that for every 1 unit increase

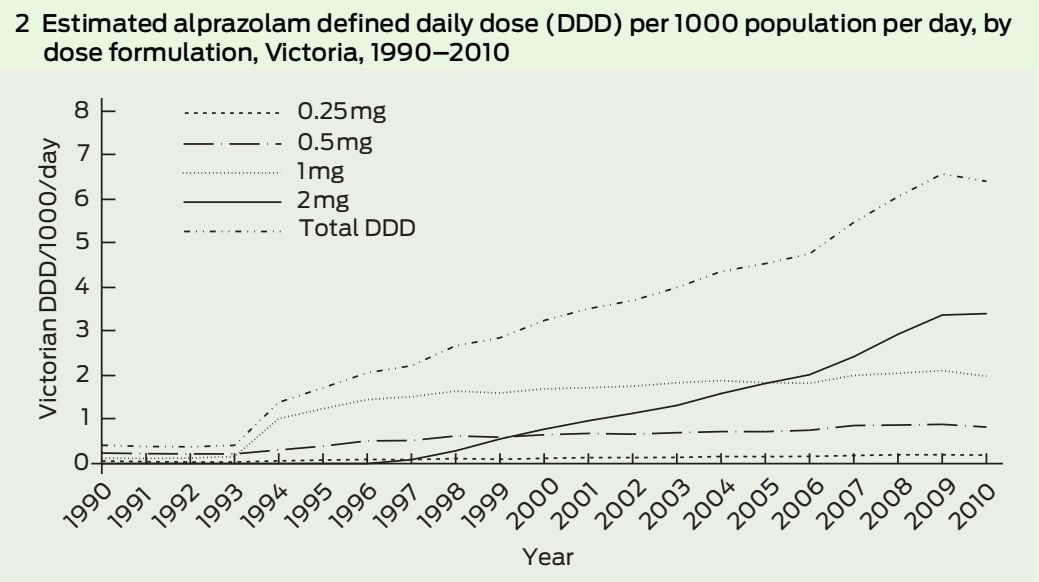

in DDD/1000/day, HRDs involving alprazolam increased at an incidence rate ratio of $2.4(95 \% \mathrm{CI}, 2.1-2.8$; $P<0.001)$. Box 4 shows a log linear relationship between supply and the proportion of HRDs in which alprazolam was detected.

\section{Discussion}

Our study over the 21 years from 1990 to 2010 showed a number of interesting trends in alprazolam prescribing and supply and its relationship to HRDs in Victoria. First, the supply of alprazolam increased despite its status as a second-line treatment for its approved indications; second, the increase in the supply of the high-dose formulation was disproportionate to the increase in other formulations; and third, the rate of detection of alprazolam in HRDs increased more rapidly after 2005, concurrently with other reports of increasing harm among PWID. ${ }^{13}$ The association between the detection of alprazolam in HRDs and alprazolam supply was strong and significant. While alprazolam may be more toxic in overdose than other benzodiazepines, ${ }^{9}$ the accelerated rate of detection in this population since 2005 could reflect an increased preference for and use of alprazolam, ${ }^{1}$ particularly the high-dose formulation, among heroin users.

This raises questions about the increased prescribing of a drug not preferred for treatment of its primary indication, ${ }^{8,18}$ and for which little evidence exists for effectiveness beyond short-term use. ${ }^{4}$ This is especially important given that it may be more toxic in overdose. ${ }^{9}$ We have shown that the proportion of HRDs in which this benzodiazepine was detected increased over time as supply 
3 Number of heroin-related deaths (HRDs) and proportion of cases in which alprazolam was detected, Victoria, 1996-2010

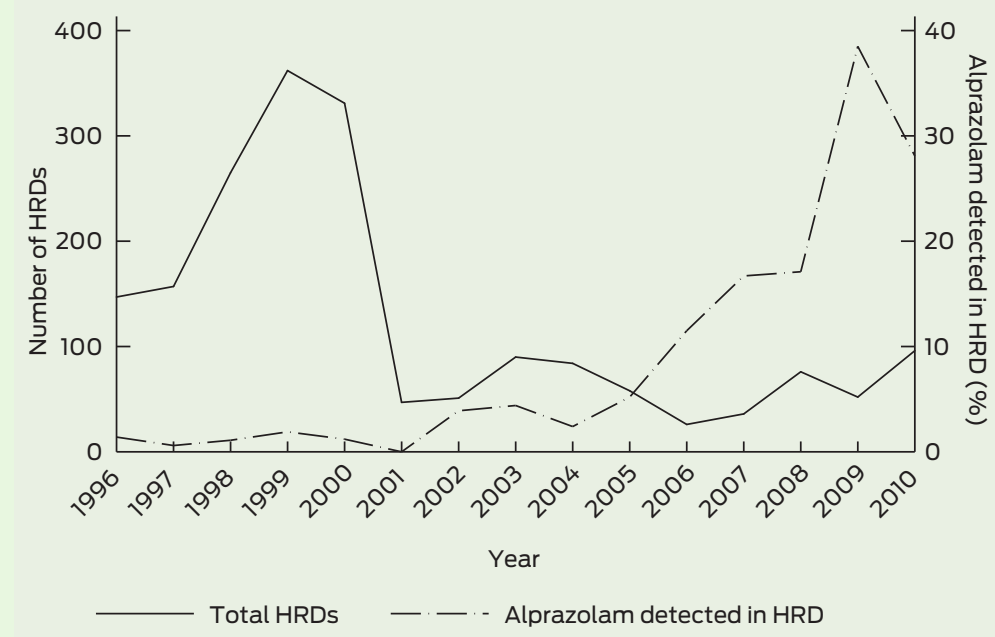

4 Relationship between annual proportion of heroin-related deaths (HRD) in which alprazolam was detected and the annual defined daily dose (DDD) per 1000 population per day, Victoria, 1990-2010*

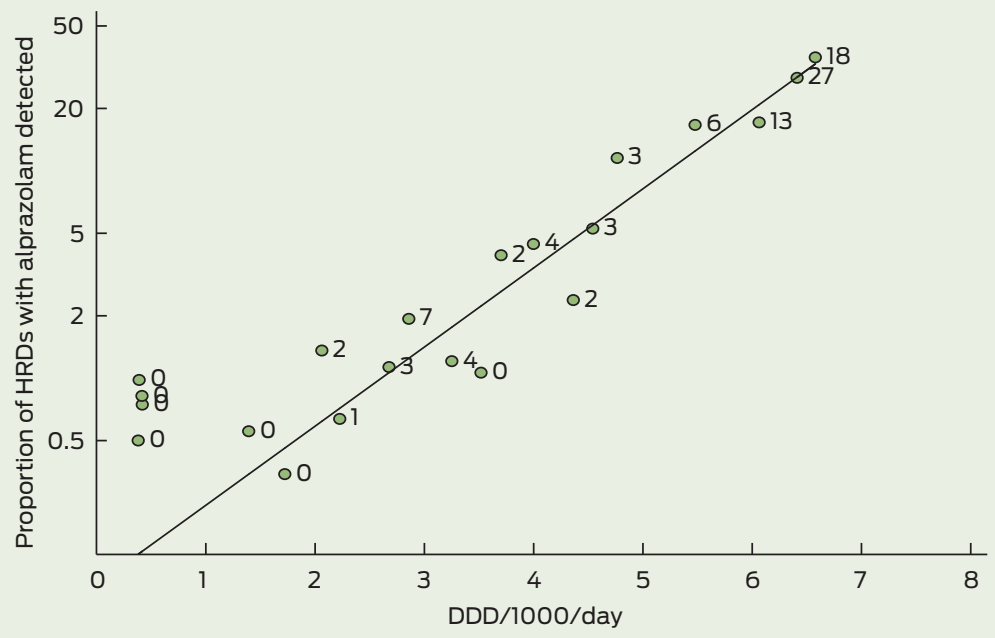

* Yearly figures are plotted and labelled with the number of alprazolam-detected HRD in that year: any years with zero alprazolam-detected HRD deaths had the number of alprazolam HRD set to 0.5 and the proportion of all HRD calculated from this.

increased. Understanding the reasons for the increasing average populationlevel consumption of alprazolam may help to decrease its supply and the harmful effects seen among PWID. This would be consistent with a previous study that showed that the average consumption of potentially harmful products such as salt and alcohol predicts the number of people affected in the statistically "deviant" tail end of a population distribution. ${ }^{16,19}$

The number of HRDs has remained fewer than during the heroin glut in the late $1990 \mathrm{~s},{ }^{20}$ which led to the peak in deaths shown in 1999. The lower numbers are likely to reflect trends in heroin supply and should not be interpreted as evidence that alprazolam is relatively safe.

A relative strength of our study is the reporting of all Victorian HRDs spanning a 21-year period, enabling the identification of long-term trends in alprazolam used shortly before death. These data provide valuable information for the future prevention of deaths among people who use heroin. In addition, the prescription data and DDD calculations are estimates of the total number of prescriptions dispensed, based on data from the ASM and Medicare. Incorporating the ASM data improves the accuracy of total prescription volume through the inclusion of private prescriptions.
The finding of a strong and statistically significant association between detection of alprazolam in cases of HRD and its supply in the community is useful for generating a hypothesis about possible causes of increasing detection of this drug in cases of HRD. However, this does not mean a causal relationship exists between the increasing alprazolam supply and such deaths. The contribution of alprazolam to deaths involving multiple drugs is difficult to determine, and it is therefore not possible to specify the proportion of cases of drug toxicity due to combined drugs where alprazolam contributed directly to death. ${ }^{21}$ We used detection of alprazolam as an indication of use by PWID, rather than contribution to death per se.

The absolute number and rate of cases of HRD in which alprazolam was detected has increased substantially since 2005. Concern about the misuse of alprazolam in 2010 led to a request to the Australian National Drugs and Poisons Schedule Committee to reschedule it to the more restrictive Schedule $8 .^{22}$ Among the committee's stated reasons for not doing so at that time was that there was insufficient evidence of a problem.

This study provides further evidence of the increasing problem, perhaps involving high-dose formulations, of use of diverted medications among PWID. ${ }^{1}$ Given the growing concerns with alprazolam use among PWID and its increasing involvement in HRDs, supply control measures such as better monitoring and surveillance (including real-time prescription monitoring), rescheduling to Schedule 8 , and education of health professionals - are warranted. Provision of information about the risks of concurrent use of opioids and alprazolam to PWID is also essential.

Acknowledgements: We are grateful to Damien Jolley and Rory Wolfe of Monash University for providing statistical advice; the PBAC Drug Utilisation SubCommittee for extracting ASM national prescription volume data; and Katayoon Yazdani for assisting in the compilation of Medicare Australia data.

Angela Rintoul is currently funded through an Australian Postgraduate Award scholarship. Some of this work was completed during her participation in the Victorian Public Health Training Scheme, funded by the State of Victoria through the Department of Health, while on placement with the Drugs Policy Unit at the Victorian Department of Health.

The views and conclusions in this article are ours and do not necessarily represent those of the Department of Health.

Competing interests: Suzanne Nielsen has worked in an unpaid capacity as an investigator on projects funded by 
untied educational grants from Reckitt-Benckiser (RB) She has not received any direct funding. Louisa Degenhardt has received untied educational grants from RB to undertake postmarketing surveillance of suboxone tablet and film products in Australia. Malcolm Dobbin has received an honorarium from Pfizer for lectures, which was donated to charity. Neither RB nor Pfizer had knowledge of, or input into, this paper.

Received 20 Jun 2012, accepted 28 Oct 2012

1 Horyniak D, Reddel S, Quinn B, Dietze P. The use of alprazolam by people who inject drugs in Melbourne, Australia. Drug Alcohol Rev 2012; 31: 585-590.

2 Chen KW, Berger CC, Forde DP, et al. Benzodiazepine use and misuse among patients in a methadone program. BMC Psychiatry 2011; 11 90. doi: 10.1186/1471-244X-11-90.

3 Jones JD, Mogali S, Comer SD. Polydrug abuse: a review of opioid and benzodiazepine combination use. Drug Alcohol Depend 2012 125: 8-18.

4 Lader M. Benzodiazepines revisited - will we ever learn? Addiction 2011; 106: 2086-2109.

5 Kirwan A, Dietze P, Lloyd B. Victorian drug trends 2011: findings from the Illicit Drug Reporting System (IDRS). Sydney: National Drug and Alcohol Research Centre, University of New South Wales, 2012 http://ndarc.med.unsw.edu.au/ sites/ndarc.cms.med.unsw.edu.au/files/ndarc/ resources/VIC_IDRS_2011.pdf (accessed Nov 2012).

6 Dietze P, Jolley D, Fry C, Bammer G. Transient changes in behaviour lead to heroin overdose: results from a case-crossover study of non-fatal overdose. Addiction 2005; 100: 636-642.

7 White JM, Irvine RJ. Mechanisms of fatal opioid overdose. Addiction 1999; 94: 961-972.
8 Moylan S, Giorlando F, Nordfjaern T, Berk M. The role of alprazolam for the treatment of panic disorder in Australia. Aust N Z J Psychiatry 2012 46: 212-224.

9 Isbister GK, O'Regan L, Sibbritt D, Whyte IM Alprazolam is relatively more toxic than other benzodiazepines in overdose. Br J Clin Pharmacol 2004: 58: 88-95.

10 Nielsen S, Lintzeris N, Lee N, et al. Pharmacodynamic interactions of alprazolam in methadone and buprenorphine naloxone patients [abstract for oral communication]. College on Problems of Drug Dependence 70th Annual Scientific Meeting; 2008 Jun 14-19; San Juan, Puerto Rico. http://www.cpdd.vcu.edu/ Pages/Meetings/CPDD08AbstractBook2.pdf (accessed Nov 2012).

11 Lintzeris N, Nielsen S. Benzodiazepines, methadone and buprenorphine: interactions a nd clinical management. Am J Addict 2010; 19: 59-72.

12 Jenkinson R, O'Keeffe B. Victorian drug trends 2005: findings from the Illicit Drug Reporting System (IDRS). National Drug and Alcohol Research Centre Technical Report No. 256 Sydney: NDARC, University of New South Wales, 2006. http://ndarc.med.unsw.edu.au/sites/ ndarc.cms.med.unsw.edu.au/files/ndarc/ resources/TR.256.pdf (accessed Nov 2012)

13 Drugs and Crime Prevention Committee. Inquiry into the impact of drug-related offending on female prisoner numbers - interim report. Melbourne: Parliament of Victoria, 2010.

14 Mcllwraith F, Hickey S, Alati R. Benzodiazepine update: alprazolam and other benzodiazepine use among people who inject drugs. Illicit Drug Reporting System Drug Trends Bulletin, April 2012. Sydney: National Drug and Alcohol
Research Centre, University of New South Wales, 2012 http://ndarc med unswedu au/sites/ndarc. cms.med.unsw.edu.au/files/ndarc/resources/ IDRS\%20April\%202012.pdf (accessed Nov 2012).

15 Darke S, Ross J, Mills K, et al. Benzodiazepine use among heroin users: baseline use, current use and clinical outcome. Drug Alcohol Rev 2010; 29 250-255

16 Rose G, Day S. The population mean predicts the number of deviant individuals. BMJ 1990; 301 : 1031-1034.

17 WHO Collaborating Centre for Drug Statistics Methodology. ATC/DDD index 2012. http:// www.whocc.no/atc_ddd_index/ (accessed Nov 2012).

18 Verster JC, Volkerts ER. Clinical pharmacology, clinical efficacy, and behavioral toxicity of alprazolam: a review of the literature. CNS Drug Rev 2004; 10: 45-76.

19 Rose G., Khaw KT, Marmot M. Rose's strategy of preventive medicine. New York: Oxford University Press, 2008

20 Degenhardt L, Day C, Gilmour S, Hall W. The "lessons" of the Australian "heroin shortage". Subst Abuse Treat Prev Policy 2006; 1: 11

21 Wolf BC, Lavezzi WA, Sullivan LM, et al. Alprazolam-related deaths in Palm Beach County. Am J Forensic Med Pathol 2005; 26: 24-27.

22 Therapeutic Goods Administration. National Drugs and Poisons Schedule Committee. Record of reasons. 59th meeting, 22-23 June 2010. Canberra: Department of Health and Ageing: 98-110. http://www.tga.gov.au/pdf/archive/ ndpsc-record-59.pdf (accessed Apr 2012).

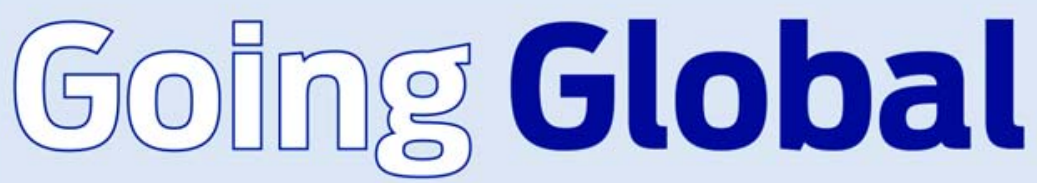

The MJA, MDA National, Nossal Global Health Prize

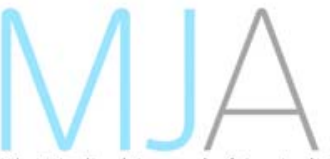

This is an international competition, open to medica students and practising and retired doctors from anywhere in the world who are working in, or have worked in, a resource-poor setting. In an essay of The Medical Journal of Australia no more than 1200 words, use a story or example from your experience of working in a resource-poor setting to illuminate a topic of global health importance. This year's theme is "leadership in global health".

The competition will be judged in two categories:

\section{Medical students 2. Medical practitioners}

Submissions deadline: Friday 14 June, via email to globalhealthcompetition@mja.com.au

The winner in each category will receive a Public Health Leadership course at the Nossal Institute for Global Health valued at $\$ 3000$ (http://www.ni.unimelb. edu.au) and $\$ 1000$ from MDA National to be used for travel expenses incurred to receive your prize.

The student prize will be presented at the annual Australian Medical Students' Association Global Health Conference and the practitioner prize will be presented at the annual Nossal Institute Global Health Forum.

The winning essays will be published in the Medical Journal of Australia. Outstanding runner-up essays may also be published.

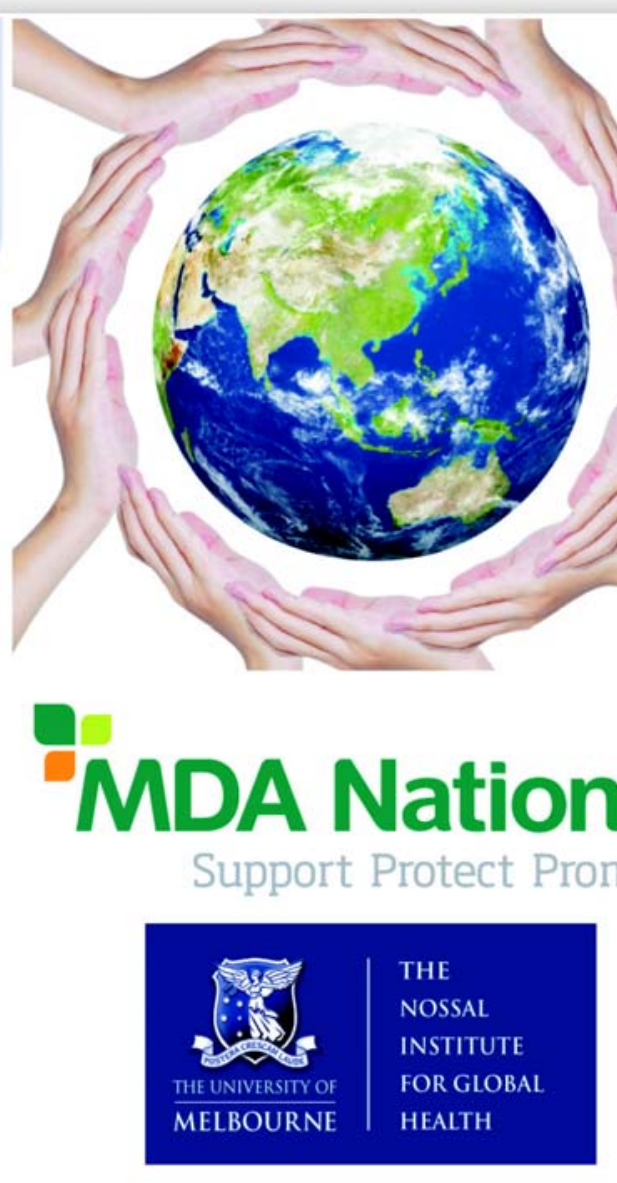

